\title{
Safety Design Strategy for the Advanced Test Reactor Primary Coolant Pump and Motor Replacement Project
}

June 2011

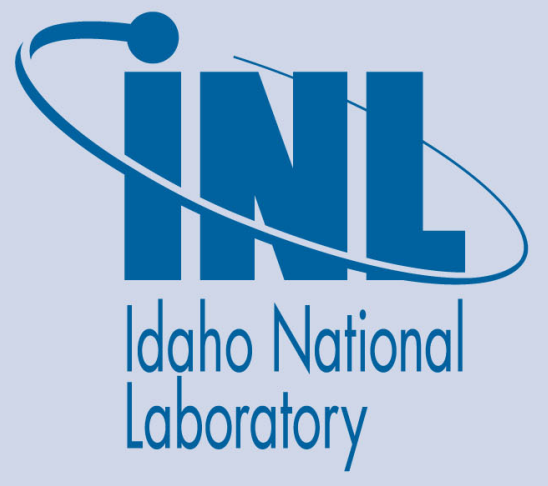

The INL is a U.S. Department of Energy National Laboratory operated by Battelle Energy Alliance 
INL/EXT-11-22380

Project No. 27410

\title{
Safety Design Strategy for the Advanced Test Reactor Primary Coolant Pump and Motor Replacement Project
}

June 2011

\author{
Idaho National Laboratory \\ Idaho Falls, Idaho 83415
}

http://www.inl.gov

Prepared for the

U.S. Department of Energy

Office of Nuclear Energy

Under DOE Idaho Operations Office

Contract DE-AC07-05ID14517 


\section{DISCLAIMER}

This information was prepared as an account of work sponsored by an agency of the U.S. Government. Neither the U.S. Government nor any agency thereof, nor any of their employees, makes any warranty, expressed or implied, or assumes any legal liability or responsibility for the accuracy, completeness, or usefulness, of any information, apparatus, product, or process disclosed, or represents that its use would not infringe privately owned rights. References herein to any specific commercial product, process, or service by trade name, trade mark, manufacturer, or otherwise, does not necessarily constitute or imply its endorsement, recommendation, or favoring by the U.S. Government or any agency thereof. The views and opinions of authors expressed herein do not necessarily state or reflect those of the U.S. Government or any agency thereof. 


\title{
BEA Nuclear Safety Engineering
}

\section{Safety Design Strategy for the Advanced Test Reactor Primary Coolant Pump and Motor Replacement Project}

\author{
INL/EXT-11-22380
}

Revision 0

June 2011

Prepared by:
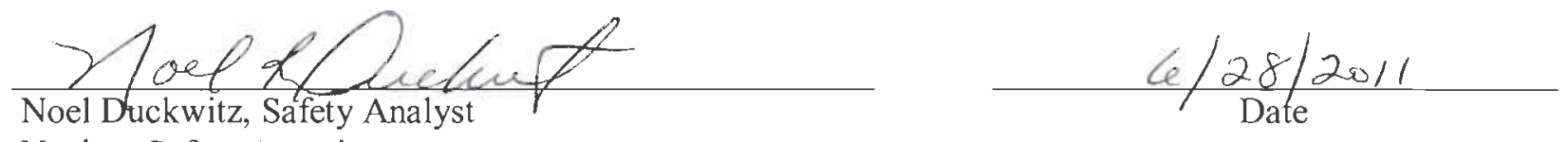

Nuclear Safety Associates

Approved by:

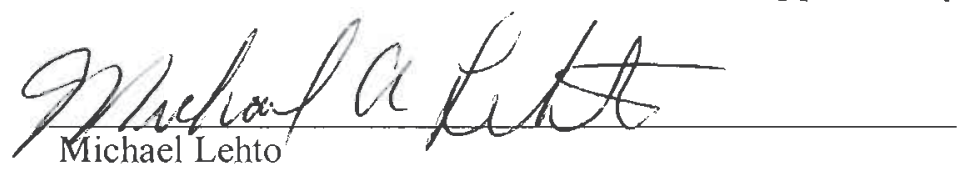

INL Facility Safety Engineering, Manager
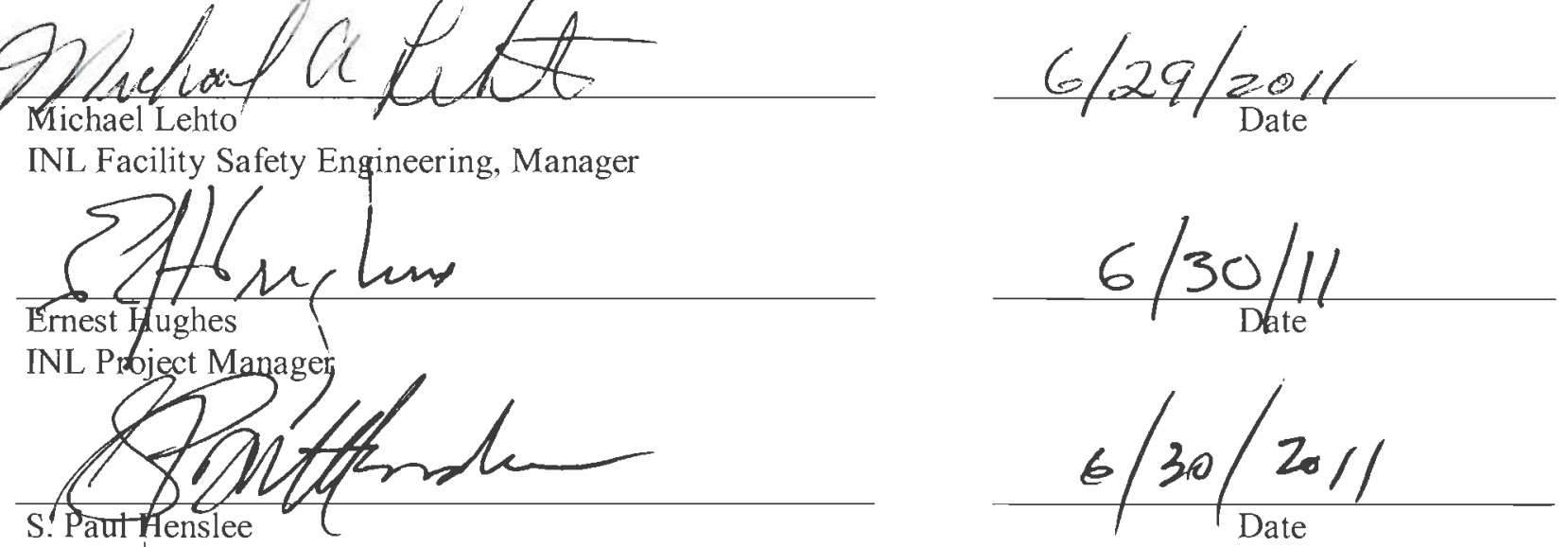

ATR Life Extension Program Director
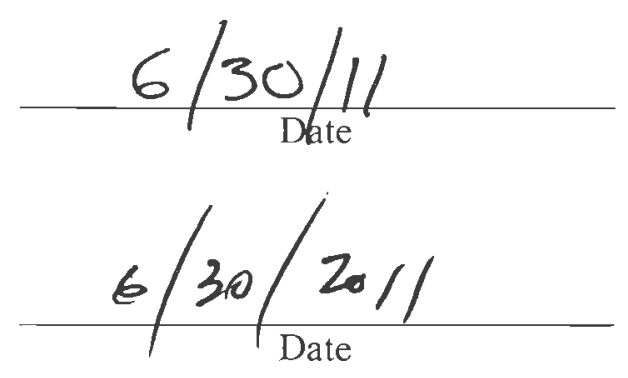
INL/EXT-11-22380

Revision 0

\section{ABSTRACT}

In accordance with the requirements of U.S. Department of Energy (DOE) O 413.3B, "Program and Project Management for the Acquisition of Capital Assets," safety must be integrated into the design process for new or major modifications to DOE Hazard Category 1, 2, and 3 nuclear facilities. The intended purpose of this requirement involves the handling of hazardous materials, both radiological and chemical, in a way that provides adequate protection to the public, workers, and the environment. Requirements provided in DOE O 413.3B and DOE O 420.1B, "Facility Safety," and the expectations of DOE-STD-1189-2008, "Integration of Safety into the Design Process," provide for identification of hazards early in the project and use of an integrated team approach to design safety into the facility. This safety design strategy provides the basic safety-in-design principles and concepts that will be used for the Advanced Test Reactor Primary Coolant Pump and Motor Replacement Project. While this project does not introduce new hazards to the ATR, it has the potential for significant impacts to safety-related systems, structures, and components that are credited in the ATR safety basis and are being replaced. Thus the project has been determined to meet the definition of a major modification and is being managed accordingly.

NOTE:

This document presents the safety design strategy for the replacement of ATR aged safetyrelated equipment and systems. It is based on the Mission Need Statement for Advanced Test Reactor Primary Coolant Pump and Motor Replacement Project which documents preliminary functional and operational requirements for the replacement equipment. These are preliminary, pre-conceptual requirements subject to revisions throughout the prescribed DOE project management process. Use of words indicating requirements or specifying intention, such as "shall" or "will," are used for the convenience of discussion or to indicate requirements or activities that are conditioned on maturation of the design and the critical decision approval corresponding to the concept/design stage for the project. Such usage should not be construed to mean that a final design selection for replacement equipment has been made. 


\section{CONTENTS}

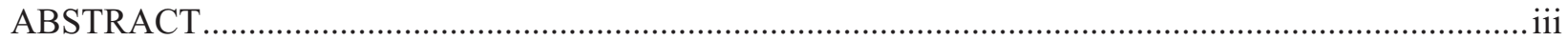

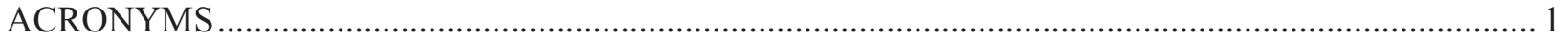

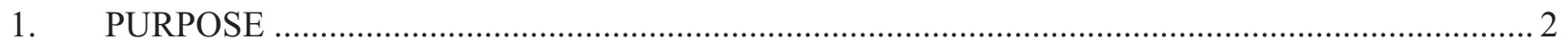

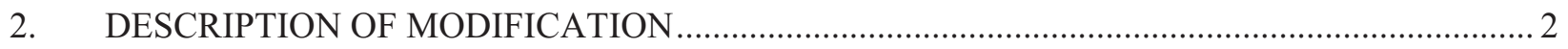

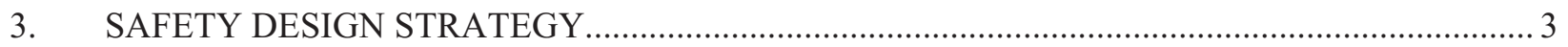

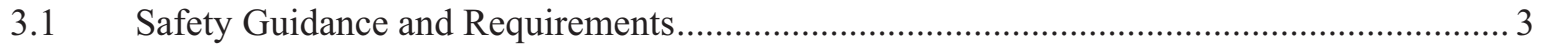

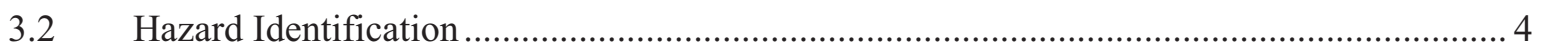

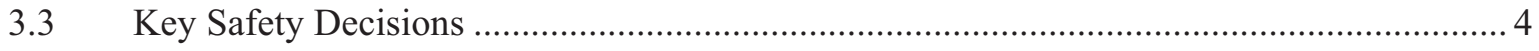

3.3.1 Seismic and Other Natural Phenomena Design Categorization ........................... 5

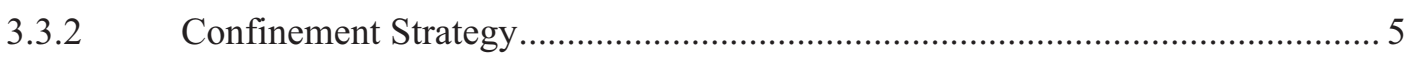

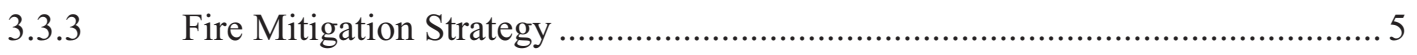

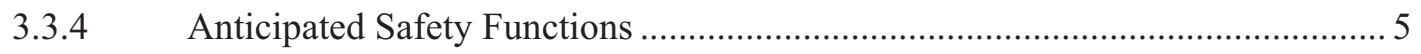

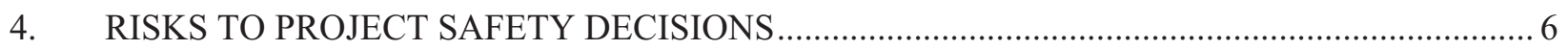

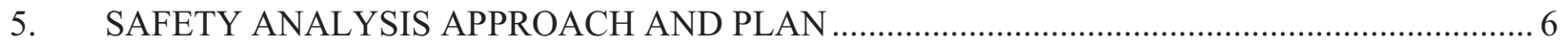

6. SAFETY DESIGN INTEGRATION TEAM - INTERFACES AND INTEGRATION .................. 8

APPENDIX A: Tailoring of CSDR Format and Content Guide .......................................................... 10

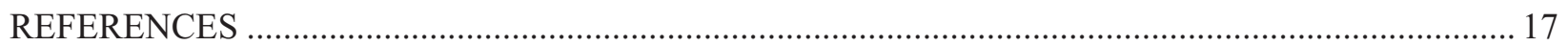




\section{ACRONYMS}

ATR

CSDR

DBA

DBT

DOE

DSA

ECP

$\mathrm{HC}$

INL

IPT

MAR

MCA

NE

$\mathrm{NPH}$

$\mathrm{OA}$

PC

PCP

PDSA

PHA

PSDR

SDS

SSC

SSE

UFSAR

VA

VFD
Advanced Test Reactor

conceptual safety design report

design basis accident

design basis threat

Department of Energy

documented safety analysis

emergency coolant pump

hazard category

Idaho National Laboratory

integrated project team

material-at-risk

material condition assessment

Office of Nuclear Energy

natural phenomena hazard

Office of Independent Oversight and Performance Assurance

performance category

primary coolant pump

preliminary documented safety analysis

preliminary hazard analysis

preliminary safety design report

safety design strategy

structures, systems, and components

safe shutdown earthquake

upgraded final safety analysis report

vulnerability assessment

variable frequency drive 


\section{Safety Design Strategy for the Advanced Test Reactor Primary Coolant Pump and Motor Replacement Project}

\section{PURPOSE}

In accordance with Department of Energy (DOE)-STD-1189-2008, "Integration of Safety Into the Design Process," this safety design strategy (SDS) for the Advanced Test Reactor Primary Coolant Pump and Motor Replacement Project at the Idaho National Laboratory (INL) describes the overall safety strategy; describes the strategy for certain high-cost, safety-related design decisions; identifies key assumptions or inputs that may represent potential risks to design decisions; and identifies expected safety deliverables through the project. In accordance with the requirements of DOE O 413.3B, "Program and Project Management for the Acquisition of Capital Assets,"2 safety must be integrated into the design process for new or major modifications to DOE Hazard Category (HC) 1, 2, and 3 nuclear facilities. Safety analysis documentation will meet the requirements of 10 CFR 830, "Nuclear Safety Management," Subpart B, "Safety Basis Requirements."

\section{DESCRIPTION OF MODIFICATION}

The Advanced Test Reactor (ATR), located in the Advanced Test Reactor Complex of the INL, was constructed in the 1960s for the purpose of irradiating reactor fuels and materials. Other irradiation services, such as radioisotope production, are also performed at the ATR.

The continued safe and reliable operation of ATR is critical to the DOE Office of Nuclear Energy (NE) mission. While ATR is safely fulfilling current mission requirements, a variety of aging and obsolescence issues challenge ATR engineering and maintenance personnel's capability to sustain ATR over the long term. First documented in a series of independent assessments, beginning with an Office of Independent Oversight and Performance Assurance (OA) Environmental Safety and Health Assessment conducted in $2003,{ }^{4}$ the issues were validated in a detailed material condition assessment (MCA) conducted as a part of the ATR Life Extension Program in 2007. Accordingly, near term replacement of aging and obsolete original ATR equipment has become important to ensure ATR capability in support of NE's long term national missions. To that end, a mission need statement has been prepared for a nonmajor system acquisition projects. ${ }^{6}$ The Primary Coolant Pump and Motor Replacement Project will replace the four obsolete, original primary coolant pumps (PCPs) and motors. Completion of this and other age-related projects will resolve major age-related operational issues plus make a significant contribution in sustaining the ATR safety and reliability profile.

The ATR MCA validated ATR staff concerns related to the long-term sustainability and reliability of the plant's four HSB Bingham horizontal centrifugal PCPs. Four pumps and associated drive motors are currently installed. Normal reactor operation requires two or three pumps to be operating with one pump idle (an installed spare). The pumps and their peripherals, including their motors and the butterfly valve (flow control valve to control reactor pressure differential) installed in the PCP discharge piping, are all original plant equipment. The pump manufacturer is no longer in business and, consequently, the pumps lack adequate vendor spares and technical support. Plant personnel must work with secondary market vendors to obtain support beyond in-house engineering and support crafts' capabilities. The equipment obsolescence issues are exacerbated by the antiquated pumps' design requiring high maintenance mechanical seals (a primary coolant leak source) plus a similarly high maintenance mechanical coupling between the pumps and their motors. Both of the ancillary components are of antiquated design making them increasingly difficult to maintain due to a similar lack of vendor support. 
The balance/flow control valve, flanged and bolted into the pump discharge piping, presents its own set of vulnerabilities, including minor primary coolant flange leaks and related contamination issues. Finally, the antiquated pump configuration imposes a number of high cost maintenance protocols and visual checks to verify pump readiness/leak-rate acceptability before every plant start-up. The pre-start-up checks also require time consuming and costly radiation-related space entry and exit protocols as a consequence of the above mentioned contamination issues. All these PCP related issues will be mitigated by replacing the plant's installed pumps and peripherals with equivalent current technology equipment.

Functionally equivalent replacement pumps matching all currently specified operating parameters are commercially available for use in nuclear service. Now of a leak-proof design, replacement pumps will eliminate the need for pre-startup leak checks, the consequent pump room contamination issues and minimize the current burden on ATR operations and maintenance staffs. Review of available pump designs support the option of variable speed capability via installation of variable frequency drive (VFD) controllers. Incorporating this new technology feature will potentially eliminate the current ATR requirement for separate emergency coolant pumps (ECPs), further reducing operations and maintenance staff burden at ATR. Finally, premised on projected mission scenarios, the replacement pumps can be designed for a minimum forty year service life while requiring virtually no service driven maintenance. These latter features, available with current technology pumps, will result in enhanced safety and reliability by design and, over their life-cycle, largely eliminate current maintenance requirements. Preliminary functional and operational requirements and criteria for the PCP replacement include the following:

- $\quad$ Provide flow rates and pressure equivalent to the currently installed PCPs

- $\quad$ Operate with the lowest achievable leak rate

- $\quad$ Provide sufficient emergency flows to support potential elimination of the installed ECPs

- Provide variable frequency drive to support potential removal of the existent flow control valve

- $\quad$ Design for a minimum 40-year design life.

\section{SAFETY DESIGN STRATEGY}

The overall safety strategy for the ATR Primary Pump and Motor Replacement Project is presented in the following sections.

\subsection{Safety Guidance and Requirements}

Pre-conceptual design for the new ATR Primary Pump and Motor Replacement Project is substantially based on functionally like-for-like replacement of aged safety-related equipment and/or systems. Like-for-like replacement, in itself, does not lead to the conclusion that the project constitutes a major modification per the guidance of DOE-STD-1189. ${ }^{1}$ However, due to the obsolescence of the aged equipment designs and the technological advances over more than four decades since ATR construction, the pre-conceptual design strategy includes system modifications that benefit from improvements in equipment designs and technological advances. The development of this strategy requires careful attention to maintaining adherence to applicable and accredited engineering and nuclear safety design criteria (e.g., active seismic qualification, redundancy and diversity for safety functions) to ensure no adverse impacts to their designated safety functions. Based on these considerations, it is concluded that this project constitutes a major modification, ${ }^{7}$ and this SDS is tailored accordingly.

Protection of the public, workers, and environment from hazards associated with operation, maintenance, and modification of the ATR is assured through compliance with the provisions of IAG-31 "INL Authorization Agreement for the Advanced Test Reactor (ATR) Complex ATR Facility,", the INL 
Authorization Agreement for the ATR Complex ATR Facility. Commitments identified in the authorization agreement include operation of the ATR facility in accordance with the operational controls specified in the Safety Basis as defined by LST-100, "INL Safety Basis List for Advanced Test Reactor Facility." "The safety basis provides the analysis of facility hazards, specifies the controls necessary to prevent and mitigate the hazards, and defines safety management programs which afford a level of safety to the public, workers, and environment. The primary safety basis documents are SAR-153, "Upgraded Final Safety Analysis Report for the Advanced Test Reactor,"10 (UFSAR) and TSR-186, "Technical Safety Requirements for the Advanced Test Reactor." "The safety-in-design approach for this project is through compliance with DOE-STD-1189 and the design commitments as stated in the UFSAR Section ES-1.1.1 as follows:

The design commitments include the assumed physical configuration of the important-to-safety and safety-related structures, systems, and components (SSC); and the facility-specific general design criteria; and the stated requirements for modifications for important-to-safety and safety-related SSC. There are design commitments in Chapters 1, 2, 3, 4, 5, 6, 7, 8, 9, 10, 11, 12, 15, 18, and 20. While design commitments are not specifically identified in the UFSAR, design commitments are preserved through the facility configuration control and the facility modification processes. Design commitments are identified as requirements in the facility modification process or the modification supports a change in the design commitment.

The design and safety evaluation will be completed in accordance with requirements delineated in DOE-STD-1189. A tailored approach will be used, focused on ensuring that replacement safety-related SSCs continue to fulfill the credited safety functions and do not introduce new, adverse failure modes. Existing UFSAR analyses will be updated as necessary where system response models are affected by the operational characteristics of the replacement equipment. The updated models/analyses and updated probabilistic risk assessment will confirm that the project maintains or reduces the core damage frequency for ATR.

\subsection{Hazard Identification}

The principal hazards for ATR are those associated with the radioactive inventory for reactor operations. The ATR material-at-risk (MAR) consists of the reactor core, radioactive material (irradiated fuel elements and other hardware) stored in the canal, isotope production targets, experiments containing fuel, and non-fueled components. The ATR is a Category A reactor with an operating power level up to $250 \mathrm{MW}_{\mathrm{t}}$ and as such, has a radioactive material inventory with the potential for significant off-site consequences. The ATR is classified as a Hazard Category - 1 (HC-1) nuclear facility in accordance with Department of Energy standards for hazard classifications of nuclear facilities. ${ }^{12}$

The proposed project has no effect on the quantity of MAR. No new hazards are introduced by this project that could potentially drive identification of new safety-class or safety-significant SSCs. Where aged safety-related SSCs are being replaced, the design process will ensure careful attention to maintaining adherence to applicable and credited engineering and nuclear safety design criteria (e.g., active seismic qualification, redundancy, and diversity for safety functions) to ensure no adverse impacts to their designated safety functions. This also includes the appropriate derivation and assignment of the safety-related designation for the replacement SSCs.

\subsection{Key Safety Decisions}

Decisions will be made during the initial project life cycle that will affect the eventual design and construction/installation of the SSCs for the ATR Primary Pump and Motor Replacement Project. Those 
key safety decisions that could potentially result in significant cost are addressed herein consistent with the hazard categorization for ATR.

\subsubsection{Seismic and Other Natural Phenomena Design Categorization}

Natural phenomena hazard (NPH) categorization is dependent upon the assigned SSC safety category. SSCs at ATR are currently classified into two categories: (a) safety-related and (b) nonsafetyrelated. The term "safety-related" ${ }^{13}$ refers to those SSC that are relied upon during or following designbasis events to ensure (a) the integrity of the primary coolant pressure boundary, (b) the capability to shut down the reactor and maintain it in a safe shutdown condition, and (c) the capability to prevent or mitigate the consequences of accidents that result in potential off-site exposures comparable to the 10 CFR 100, Appendix A, "Seismic and Geologic Siting Criteria for Nuclear Power Plants," "14 guidelines. For ATR, safety-related is equated to safety class as defined in 10 CFR 830.

Safety-related SSC have been divided into two classes for the purpose of establishing seismic, wind, and flood performance requirements in accordance with Regulatory Guide $1.70 .{ }^{15}$ These classes are Seismic Category I and Non-Seismic Category I. Those safety-related SSC whose functions are needed to mitigate the effects of the safe shutdown earthquake (SSE) are designated Seismic Category I in

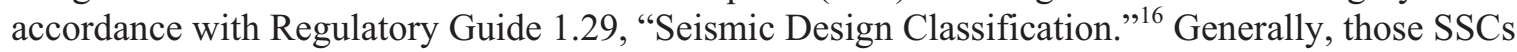
designated as safety-related are also designated Seismic Category I.

Generally speaking for this project at the current pre-conceptual stage, SSCs that are replacing aged safety-related equipment will also be categorized as safety-related and classified Seismic Category I. Replacement safety-related Seismic Category I SSCs will be designed to Performance Category 4 (PC-4) standards (DOE-STD-1020, "Natural Phenomena Hazards Design and Evaluation Criteria for Department of Energy Facilities"17), inclusive of all support systems necessary for the SSC to perform its safetyrelated function. The discussion for NPH categorization referred to in Appendix A (Section A.1) of DOE-STD-1189 utilizing ANSI/ANS 2.26-2004, "Categorization of Nuclear Facility Structures, Systems and Components for Seismic Design," "18 establish seismic design bases is applicable to DOE nonreactor nuclear facilities. ATR, being a Class A reactor, will continue to apply the criteria from DOE-STD-1020 and -1021, "Natural Phenomena Hazards Performance Categorization Criteria for Structures, Systems, and Components,"19 for this project.

\subsubsection{Confinement Strategy}

The confinement strategy for the ATR is discussed in Section 6.2 of the UFSAR and is largely unaffected by the ATR Primary Pump and Motor Replacement Project.

\subsubsection{Fire Mitigation Strategy}

Since the ATR Primary Pump and Motor Replacement Project, as envisioned in the current preconceptual stage, does not include construction of any new structures, the fire mitigation strategy is to maintain the existing ATR fire safety posture for any modifications to existing structures. Any modifications to existing structures (e.g., piping or power penetrations through existing credited fire barriers) will be designed to maintain the existing, credited fire safety design for the SSC being modified. Fire safety analysis will be drafted and updated consistent with the maturation and phase of the design, per the requirements of DOE O 420.1B Chapter II. ${ }^{20}$

\subsubsection{Anticipated Safety Functions}

At the current pre-conceptual phase for this project, the evaluation of alternative designs and selection of preferred options may result in the derivation of new or modification of existing safety 
functions for the safety-related SSCs being replaced. (Currently the only safety function for the PCPs is the integrity of the primary coolant pressure boundary as a passive Seismic Category I SSC.) However, based on the information available at this pre-conceptual phase, it is anticipated that the replacement SSCs will assume the safety functions of the existing safety-related SSCs being replaced. This is discussed in more detail for the project in Section 2 above. The safety functions will be developed in more detail through further development of the safety strategy with the subsequent design phases and maturation of the design for the project.

\section{RISKS TO PROJECT SAFETY DECISIONS}

Because the proposed ATR Primary Pump and Motor Replacement Project is substantially based on replacement of existing aged and obsolete original ATR equipment with functionally equivalent equipment, it does not introduce any new significant hazards requiring new accident analysis. However, the equipment being replaced by this project is credited in the current ATR safety basis as safety-related to perform various safety functions. Given the age of the current equipment and the need to replace it to overcome various obsolescence issues, it is appropriate that available technology and commercial experience, as applicable, be incorporated in the design of the replacement system. The incorporation of more recent technology and commercial experience into the design does introduce risks and concerns that the safety function is still fulfilled as effectively as or more effectively than credited in the safety basis. The safety-related designation requires careful attention to maintaining adherence to applicable engineering and nuclear safety design criteria (e.g., seismic qualification, isolation of redundant trains from common fault failures, maintaining appropriate redundancy and diversity) to ensure no adverse impacts to their designated safety functions. This is the primary risk to project safety decisions and driver for concluding that this project is a major modification per the nuclear safety management rule. ${ }^{7}$

As the project proceeds from the pre-conceptual phase to the conceptual phase and preparation of the CD-1 submittal, the risks to the project safety decision will be identified in more detail and coordinated with the preparation of the Risk Management Plan.

\section{SAFETY ANALYSIS APPROACH AND PLAN}

DOE-STD-1189 provides the guidance for determining if facility modifications constitute a major modification per the definition of 10 CFR $830 .{ }^{3}$ As stated in the standard, "Where a major modification is found to exist, an SDS must be developed that addresses (1) the need for a CSDR or PSDR (as well as the required PDSA) to support project phases, (2) the graded content of the PDSA necessary to support the design and modification, (3) the application of nuclear safety design criteria, and (4) the interface with the existing facility, its operations, and construction activities." As noted in Section 4 above, the primary driver for the conclusion that this project constitutes a major modification is to ensure through the design process that the replacement safety-related SSCs, while being updated with current technology and experience, continue to fulfill the safety functions as effectively as or more effectively than credited in the safety basis. This is the primary focus of the safety analysis approach and documentation to be developed for this project.

Consistent with the guidance stated above, the following requisite nuclear safety documentation will be developed as part of the project:

- $\quad$ Safety design strategy

- $\quad$ Conceptual safety design report (CSDR)

- $\quad$ Preliminary safety design report (PSDR) 
INL/EXT-11-22380

Revision 0

- $\quad$ Preliminary documented safety analysis (PDSA)

- $\quad$ Final documented safety analysis (DSA).

This nuclear safety documentation will be developed in accordance with DOE-STD-1189, DOE O 413.3B, and NS-18101, "INL Safety Analysis Process," "1 nuclear facility safety requirements, tailoring the above listed documents for a major modification to an existing DOE HC-1 nuclear facility as discussed in the following paragraphs.

DOE-STD-1189 Appendix H, §H.2 provides a CSDR format and content guide. This guide contains the full scope for new a DOE nuclear facility CSDR. This content must be tailored for this project to address those topics relevant to the scope of each subproject. Appendix A of this SDS contains the CSDR format and content guide with the preliminary tailoring details for this project. This tailoring will be carried through in the PSDR, which will update the CSDR consistent with the design maturation and project design phase progression.

A major modification requires the development of a PDSA per 10 CFR 830.206. Since DOE-STD-3009, "Preparation Guide for U. S. Department of Energy Nonreactor Nuclear Facility Documented Safety Analyses," 22 is not the safe harbor format for the ATR UFSAR, this SDS establishes the expectations and the format for integrating the major modifications into the ATR UFSAR, SAR-153. In lieu of a stand-alone PDSA, the following "redline strikeout" documentation shall be developed: (1) Identification of all UFSAR and TSR sections that are affected by the subproject, and (2) The revised text for those affected sections of the UFSAR and TSR as necessary to accurately reflect the facility configuration, system responses, safety SSC listing and classifications, controls, and facility safety posture with the subproject completed. The documented changes shall be supported as necessary with updated analysis for existing accidents discussed in the UFSAR. Any new failure modes introduced by the replacement SSC designs shall be identified, analyzed, and added to Chapter 15 of the UFSAR.

Project safety basis document preparation will follow the guidance of DOE-STD-1189, which is to integrate safety analysis throughout the design process. The standard is intended to implement safety-indesign philosophies listed in DOE O 413.3B and facility safety criteria listed in DOE O 420.1B.

As the project design matures, generation of other necessary safety documents and analyses will be required. These supporting documents, other than operational procedures, will include the following as appropriate:

- $\quad$ Update to ATR fire hazard analysis

- $\quad$ Engineering design files

- $\quad$ Radiation work permits

- $\quad$ Operational job safety analyses

- Industrial hygiene exposure assessments prepared in accordance with the associated INL procedures. 
INL/EXT-11-22380

Revision 0

\section{SAFETY DESIGN INTEGRATION TEAM - INTERFACES AND INTEGRATION}

The purpose of the project integrated project team (IPT) is to provide cross-functional groups of individuals organized for the specific purpose of delivering a project where the technical, management, budgetary, safety, and security interests are met. Use of IPTs is the primary tool for breaking down the walls that can exist between different organizations, different professions, and different levels within the command structure. A successful IPT brings the diverse elements together to form a unit that is willing to share information and balance priorities and ideologies in efforts to successfully execute the project mission while achieving the overall safety strategy.

The safety design integration team includes appropriate representatives from traditional worker safety disciplines, emergency management, and safeguards and security. The safety IPTs that will be used for this project include the Federal IPT, the contractor IPT, and the local project safety design integration team. Each of these IPTs consists of individuals representing diverse disciplines with specific areas of expertise and the ability to support the Federal Project Director in successful execution of the project. Membership may be full time or part time and will change as the project matures through the various phases from initiation through closeout. Membership will include federal and contractor employees and will consist of the members, or designees, the functional positions of which will be defined between CD-0 and CD-1 and the members identified.

The responsibilities of the IPTs include the following:

- $\quad$ Support the Federal Project Director

- $\quad$ Support preparation and submittal of funding request documents, as necessary, to secure project funding

- Support development of the project acquisition strategy

- $\quad$ Ensure interfaces are identified, defined, and managed to completion

- Identify, define, and manage implementation of environment, safety, health, and quality requirements

- $\quad$ Identify and define appropriate and adequate technical scope, schedule, and cost parameters

- $\quad$ Perform periodic reviews and assessments of project performance and status against established performance parameters, baselines, milestones, and deliverables

- $\quad$ Plan and participate in project reviews, audits, and appraisals, as necessary

- $\quad$ Review and comment on project deliverables, as appropriate

- $\quad$ Review change requests and support change control board actions, as appropriate

- $\quad$ Participate in readiness reviews or readiness assessments

- Support preparation, review, and approval of project completion and closeout documentation 
INL/EXT-11-22380

Revision 0

- $\quad$ Ensure that safety is fully integrated into design, construction, and operations of the HC-1 nuclear facility. 
INL/EXT-11-22380

Revision 0

\section{APPENDIX A:}

\section{Tailoring of CSDR Format and Content Guide}

DOE-STD-1189 provides the guidance for determining if facility modifications constitute a major modification per the definition of 10 CFR 830. As stated in the standard, "Where a major modification is found to exist, an SDS must be developed that addresses (1) the need for a CSDR or PSDR (as well as the required PDSA) to support project phases, (2) the graded content of the PDSA necessary to support the design and modification, (3) the application of nuclear safety design criteria, and (4) the interface with the existing facility, its operations, and construction activities." As noted in Section 4 of this SDS, the primary driver for the conclusion that this project constitutes a major modification is to ensure through the design process that the replacement safety-related SSCs, while being updated with current technology and experience, continue to fulfill the safety functions as effectively as or more effectively than credited in the safety basis. This is the primary focus of the safety analysis approach and documentation to be developed for this project.

The following sections contain the CSDR Format and Content Guide as excerpted from DOE-STD-1189, Appendix H. The guide is written broadly to address projects ranging from new construction of major DOE nuclear facilities to those lesser projects that have been subjectively determined to meet the definition of a major modification to an existing DOE nuclear facility with an operating safety basis. As inferred by the quoted statement from DOE-STD-1189, not all major modifications need a CSDR and subsequent PSDR. However, for this project, certain aspects of the CSDR are relevant to ensure integration of safety into the design process. Accordingly, the content for the CSDR and subsequent PSDR must be tailored to address those topics that are relevant for this major modification. Text detailing the graded content for this project's CSDR is appended to each section of the content guide below.

\section{CSDR FORMAT AND CONTENT GUIDE}

\section{INTRODUCTION}

\section{a. Facility and Mission Overview}

Identify the facility and present general information on the background of the facility as it relates to the use of the project scope. Present the current mission statement. Present any relevant information (e.g., short facility life cycle, anticipated future change in facility mission, approved DOE exemptions) affecting the extent of safety-in-design approaches documented in the CSDR.

\section{b. Site Location}

Provide a description of the facility location, including the physical and institutional boundaries, relationship, and interfaces with nearby facilities, facility layout, and significant external structures, systems, and components (SSC) interfaces (e.g., utilities) as they pertain to the hazard analysis. If multiple sites are under consideration, describe each of them.

\section{Section 1 Graded Content for ATR Primary Pump and Motor Replacement Project:}

To the extent that the current pre-conceptual project scope does not includes new structures, the CSDR will include, either directly or by reference to the CDR, a general ATR facility description and mission overview. Site location discussions will be limited to descriptions of the compatibility of existing machinery space envelopes with replacement equipment discussed in the conceptual design description per section 2 below. 
INL/EXT-11-22380

Revision 0

\section{CONCEPTUAL DESIGN DESCRIPTION}

\section{a. Facility Structure and Layout}

Provide information necessary to perform facility-level design basis accidents (DBAs) (as described in Section 4.2 of this Standard). Such information as basic floor plans, MAR locations within the structure, general dimensions, and dimensions significant to the hazard analysis activities is necessary. Supply information to support an overall understanding general arrangement of the facility as it pertains to hazard analyses topics to be described in later sections of the CSDR.

\section{b. Process Description}

Describe the individual processes within the facility to support understanding of the overall postulated facility-level MAR release events and safety-in-design strategies taken to prevent or mitigate the events described. Include details as necessary on basic process parameters, including summary of types and quantities of hazardous materials, energy sources, process equipment, basic flow diagrams, and operational considerations associated with individual processes or the entire facility, including major interfaces and relationships between SSCs. Information is expected only at the level of conceptual design as described in Section 4.2 of this Standard. The intent is to supply information sufficient to understand facility-level MAR release events.

\section{Section 2 Graded Content for ATR Primary Pump and Motor Replacement Project:}

Where the conceptual design includes installation of replacement safety-related equipment within existing equipment space envelopes, the CSDR will include, either directly or by reference to the CDR, layout information as discussed in section 2.a. above. This information is particularly germane to the layout of redundant trains of safety-related equipment. In addition, where replacement equipment being updated with current technology and experience that alters the current safety function process (e.g., use of variable frequency drive controlled replacement PCPs to fulfill emergency coolant pump functions), the CSDR will include the information discussed in $2 \mathrm{~b}$ above relative to the process changes.

\section{PRELIMINARY HAZARD CATEGORIZATION}

\section{a. Hazardous Material Inventories}

Estimate the total inventory (with associated uncertainties) of radionuclides, hazardous chemicals, and flammable and explosive materials used or potentially generated in facility processes. Present the results either by direct inclusion of or by reference to the hazard identification data sheets in the Preliminary Hazard Analysis (PHA). The attributes of hazards identified in this section are the basis for subsequent hazard evaluation and accident analysis in future project stages.

This inventory must describe the maximum inventories of hazardous materials that are anticipated to be in the facility during its operational life. To the extent possible, the inventory is specified by component and location within the conceptual designed facility. This should be in sufficient detail to support a facility-level PHA that would, in turn, support the definition of facility-level DBAs or bounding accidents associated with the inventory locations (e.g., tanks, storage, process vessels) and the associated preliminary lists of SC and SS SSCs.

For the purposes of preliminary facility hazard categorization (before final design), the use of Type B containers to exclude MAR from the facility inventory may be used. During final design, material in Type B containers with current certificates of compliance may be excluded from the 
INL/EXT-11-22380

Revision 0

inventory for final hazard categorization when safety analyses demonstrate that containers can withstand all accident conditions.

\section{b. Comparison of Inventories to Threshold Quantities}

Compare the radionuclide and fissile material inventories with the threshold quantities in Table A.1 of DOE-STD-1027-92, Change Notice 1, September 1997, and identify the preliminary hazard categorization. When segmentation is proposed, identify segment boundaries and hazard inventories and justify the independence of the segments. Identify the individual segment preliminary hazard categorizations.

The preliminary hazard categorization must be in compliance with DOESTD-1027, Change Notice 1, September 1997-92, as required by 10 CFR 830.202. The information compiled in the preliminary inventory of hazardous materials is used for this purpose. Note any likely issues that may change final hazard categorization, such as obvious inconsistencies with the basis of the DOE-STD-1027-92, Change Notice 1, September 1997, Table A.1. For example, if facility processes include the possibility of vaporization of radioactive materials, for which DOE-STD-1027-92, Change Notice 1, September 1997, assumed an airborne release fraction (ARF) of $1 \mathrm{E}(-3)$, it should be noted that final hazard categorization would need to be based on an ARF of 1.0. Similarly, if the facility is intended for the storage of vitrified "logs," it should be noted that an ARF of 1 E (-6) might be appropriate in final hazard categorization.

\section{Section 3 Graded Content for ATR Primary Pump and Motor Replacement Project:}

Section is not applicable and not anticipated to be part of the project CSDR unless new information develops in during subsequent project design phases.

The replacement of aging and obsolete ATR equipment is not expected to introduce any new hazardous materials.

The ATR MAR consists of the reactor core, the radioactive materials (irradiated fuel elements and other hardware) stored in the canal, isotope production targets, and experiments containing fuel and non-fueled components. The ATR is a Category A reactor with an operating power level up to $250 \mathrm{MW}_{\mathrm{t}}$ and, as such, has a radioactive material inventory with the potential for significant off-site consequences. The proposed project has no effect on the quantity of MAR or facility hazard categorization.

\section{DESIGN BASIS ACCIDENTS}

\section{a. Facility-Level DBAs}

Provide a summary table identifying postulated hazardous material release events. The goal is to provide a perspective on facility hazards by summarizing the major events or hazardous situations (e.g., fires, explosions, loss of confinement) that were postulated in the facility during the PHA activities. During the conceptual design stage, a facility layout, including process flow diagrams and locations of MAR will be developed. Bounding accident scenarios involving the MAR locations, such as fires, explosions, and seismic induced failures, can be postulated.

\section{b. Unmitigated DBA Analyses}

Appendix A and Appendix B of this Standard provide radiological dose and chemical exposurerelated criteria and guidance respectively. Appendix A criteria are to be used for the classification of SSCs as Safety Class or safety significant on the basis of unmitigated accident dose analyses and for the application of seismic design guidance of ANSI/ANS 2.26, Categorization of Nuclear Facility Structures, Systems, and Components for Seismic Design. Appendix B criteria are 
INL/EXT-11-22380

Revision 0

suggested for classification of SSCs as safety significant based on chemical hazards. Application of the criteria requires unmitigated accident analyses for the facility-level DBAs.

For each DBA:

1. Identify the release category by individual title, category (i.e., operational, natural phenomena, external) and general type (e.g., fire, explosion, spill, earthquake, tornado).

2. Describe the source-term determination for the event category. Discuss all parameters used to derive the source term. This definition includes the MAR (as derived from the hazard identification), the damage ratio (DR) and the ARF. The degree of conservatism believed to be present in the calculation needs to be consistent with DOE-STD-300994, CN 3, Appendix A, definitions and requirements.

3. Present the results of the DBA analysis, both to the collocated worker at $100 \mathrm{~m}$ and to the public according to the guidance of appendices A and B of this Standard.

4. Compare the DBA results to guidance for safety system classification and seismic design criteria of Appendix A of this Standard and the suggested criteria for chemical hazards of Appendix B of this Standard.

\section{c. Preliminary Selection and Classification of Safety SSCs}

For each DBA, the following information is presented, based on the analyses of the DBAs in the PHA and the safety classification criteria in appendices A and B of this Standard:

i. Preliminary identification of facility-level safety functions; and, if proposed, the associated Safety Class and SS structures, systems, and components (safety SSCs) and their necessary support systems;

ii. Requirements for the identified safety functions and, if proposed, for the associated safety SSCs; and

iii. Applicable structural design basis associated with each system (seismic design criteria and PC categories for other NPH).

Based on unmitigated analyses of the facility DBAs, candidate preventative and mitigative safety SSCs can be identified and classified, according to the guidance of appendices A through D.

This section provides a discussion of safety functions and design criteria for selected safety SSCs; for example, the required safety functions for the confinement, active ventilation, fire protection, and electrical power and distribution SSCs. This section should also describe the rationale from a Safety-in-Design perspective for the following major systems (including NPH design expectations) recognized as having significant cost impact if changed later in the project cycle:

- $\quad$ Facility structure;

- $\quad$ Facility hazardous material confinement;

- Fire protection; and

- $\quad$ Emergency power

As described in Appendix A, DOE is adopting ANSI/ANS 2.26, Categorization of Nuclear Facility Structures, Systems, and Components, for the purpose of new facility and major modification design. Once the Seismic Design Category is identified for facility SSCs, the appropriate Limit State for those SSCs should be selected, based on their safety function. See Appendix A and ANSI/ANS 2.26 and its appendices for guidance. 


\begin{abstract}
Section 4 Graded Content for ATR Primary Pump and Motor Replacement Project:
The derivation of ATR design basis accidents (DBAs) is discussed in section ES-3.2 of the ATR UFSAR (SAR-153) and detailed accident descriptions and system responses are discussed in chapter 15 . The primary focus for this project will be on any impact that replacement SSCs may have on the system accident response as discussed in the accident analysis. The project CSDR will include a table or listing of the chapter 15 events that are impacted (i.e. as a preventive or mitigative feature or in terms of system response) by the present SSC being replaced by the project. The listing entry will include an assessment of the impact with the replacement $\mathrm{SSC} /$ design to include changes in failure modes that may accompany the integration of upgraded technology with the selection for the replacement design. The assessment will be supported by new or updated accident analysis (including probabilistic risk assessment) as necessary. Safety functions and categorization (safety and seismic design categorization) for each replacement SSC will be detailed.

Where the conceptual design includes replacement safety-related equipment, the CSDR will include discussion of seismic categorization for the equipment as well as fire protection for the safety-related replacement equipment.

The discussion for NPH categorization referred to above in Appendix A (section A.1) of DOE-STD-1189 is applicable to DOE non-reactor nuclear facilities. ATR, being a Class A reactor, will continue to apply the criteria from DOE standards 1020 and 1021 for this project.
\end{abstract}

\title{
5. SECURITY HAZARDS AND DESIGN IMPLICATIONS
}

This section, depending on security classification considerations, may have to be a placeholder that references a classified report. That report would describe the facility design aspects that respond to design basis threat (DBT) information, the results of the Vulnerability Assessment (VA), and would address how the security design aspects take into account facility safety issues in protection of workers and the public.

DOE Security Orders (i.e., 470 series) have requirements that may affect design and the safety aspects thereof for some facilities. These directives should be reviewed as part of the design process. In particular, there are requirements regarding the DBT, the implementation of which may have implications regarding public and worker safety. The concept considered in ensuring that both the security requirements and safety requirements are satisfied for any security installation at a facility meeting the DBT is that the approach (1) encompasses all threats for which the security system is required to be designed based on the DBT and/or VA, (2) be employed in an effective manner to assure neutralization and protect the national security, and (3) assures that safety requirements are met.

\section{Section 5 Graded Content for ATR Primary Pump and Motor Replacement Project:}

At the current level of information for the project, it is not anticipated that the replacement of aging and obsolescent equipment will have any impact on the ATR facility design in response to the DOE O 470.3B Graded Protection Policy. However, as a minimum, the CSDR will include a discussion affirming this conclusion. 
INL/EXT-11-22380

Revision 0

\section{NUCLEAR SAFETY DESIGN CRITERIA}

\section{a. Approach for Compliance with Design Criteria}

Provide a listing of the applicable safety design criteria of DOE O 420.1B, Facility Safety, and a brief summary of the implementation approach being taken in the project for each design-related criterion. Programmatic criteria are not expected to be discussed. This section is meant to be a description of, or a roadmap to, the specific information that demonstrates the implementation approaches for the various criteria, not a detailed re-write of information included in other sections of the CSDR or other available project documentation.

Note that some of the attributes applicable to the project may not be items that would be addressed by the hazards analysis process (e.g., provisions for decontamination and decommissioning and provisions for radiological controls for ALARA expectations). These items still are expected to be included as applicable criteria and discussed in this section of the CSDR to demonstrate that the key items that will be in the final DSA are being considered appropriately in the conceptual design process.

The nuclear safety design criteria of DOE O 420.1B are primarily located in both the Order and Attachment 2 to the order in Chapter I, "Nuclear and Explosives Safety Design Criteria"; but additional applicable safety design criteria can be found in Chapter II, "Fire Protection"; Chapter III, "Nuclear Criticality Safety"; and Chapter IV, "Natural Phenomena Hazards Mitigation." The implementation guides for these chapters should also be followed.

To the extent possible at this stage of design, for the selected safety SSCs, tie the structure or system level specific criteria (e.g., DOE-STD-1020-2002, ANS 2.26 for natural phenomena criteria in DOE O 420.1B) to the DOE O 420.1B criterion that it satisfies. Programmatic criteria (e.g., system engineer program, configuration management) are not expected to be discussed.

\section{b. Exceptions to Design Criteria}

Provide, for any exception to the high-level safety design criteria in DOE O 420.1B, or the implementing standards listed in DOE G 420.1-1 and listed in Section 6.a, the project's alternative criterion and a justification for the alternative. The justification must show why the alternative is an acceptable criterion or standard.

\section{Section 6 Graded Content for ATR Primary Pump and Motor Replacement Project:} A listing of the of the applicable safety design criteria of DOE O 420.1B, Facility Safety, and a brief summary of the implementation approach being taken for each designrelated criterion will be provided.

\section{OTHER CONSIDERATIONS}

\section{a. Planned Studies or Analyses}

Describe any key planned technical studies essential for development or validation of the safety design basis that will be accomplished in preliminary/final design. These studies may be necessary to confirm key assumptions or key process component equipment selections that could affect safety. The primary source for this information is the PHA and Safety Strategy.

\section{b. Safety-in-Design Risks and Opportunities}

Summarize the Safety-in-Design risks and opportunities from the CDR. The intent of this summary is to provide an overall perspective of the risks and opportunities associated with the Safety-in-Design strategies considering the maturity of the project, the remaining technical studies, and the mitigative and preventive strategies selected for the recognized preliminary 
INL/EXT-11-22380

Revision 0

design basis events. Describe only key risks and opportunities and the associated mitigation strategies that are important to be recognized by the approval authority. These discussions are intended to support a risk-informed decision regarding progressing to preliminary design.

\section{c. Lessons Learned From Previous Experience Involving Major Systems}

In this section, discuss the logic used to select the safety-related functions for SSCs that may generate significant cost changes to the project if changed in later stages of the project. This logic may be based on lessons learned from previous experience involving major systems.

It is important for safety SSCs be identified early in the design process. Otherwise, costly upgrades to the facility design could occur. When a safety classification is unclear for a major SSC (based upon very preliminary analysis), a higher level of categorization should be the default position early on until the analysis progresses to the point that a confident and defensible determination can be made for a lower level.

When followed correctly, the hazard and accident analysis process should supply a reproducible logic for safety SSC choices. Specific examples of potential safety SSCs include the following:

- $\quad$ Fire suppression;

- $\quad$ Fire detection;

- Confinement ventilation;

- $\quad$ Emergency power;

- Nuclear criticality design features and alarms;

- Seismic design, including addressing level of confinement for primary

- $\quad$ Confinement system (building structure); and

- $\quad$ Flammable gas controls.

These items have the potential for large cost and schedule impacts if their design expectations are added later in the project life cycle.

Section 7 Graded Content for ATR Primary Pump and Motor Replacement Project:

The project CSDR will discuss other considerations consistent with the guidance above. 
INL/EXT-11-22380

Revision 0

\section{REFERENCES}

1. DOE-STD-1189-2008, "Integration of Safety into the Design Process," Department of Energy, 2008.

2. DOE Order 413.3B, "Program and Project Management for the Acquisition of Capital Assets," Department of Energy, November 2010.

3. 10 CFR 830, "Nuclear Safety Management," Subpart B, "Safety Basis Requirements," Code of Federal Regulations, Office of Federal Register.

4. DOE Summary Report, "Inspection of Environment, Safety, and Health Management and Emergency Management of the Idaho Operations Office and Idaho National Engineering and Environmental Laboratory," Office of Independent Oversight and Performance Assurance (OA), September 2003.

5. NISYS-1255-TR016/R0, “Advanced Test Reactor Material Condition Assessment Summary Report,” December 2007.

6. "Mission Need Statement for ATR Primary Pump and Motor Replacement Project," Draft, May 2011.

7. INL/EXT-11-22063, “10 CFR 830 Major Modification Determination for Replacement of ATR Primary Coolant Pumps and Motors," Rev. 0, May 2011

8. IAG-31, "INL Authorization Agreement for the Advanced Test Reactor (ATR) Complex ATR Facility," Rev. 8, February 2011.

9. LST-100, "INL Safety Basis List for Advanced Test Reactor Facility,” Rev. 41, February 2011.

10. SAR-153, "Upgraded Final Safety Analysis Report for the Advanced Test Reactor," Rev. 30, February 2011.

11. TSR-186, “Technical Safety Requirements for the Advanced Test Reactor," Rev. 25, February 2011.

12. DOE-STD-1027-92, "Hazard Categorization and Accident Analysis Techniques for Compliance with DOE O 5480.23, Nuclear Safety Analysis Reports," U.S. Department of Energy, September 1997.

13. House, R. K., "Bases for Designation of Safety-Related Equipment in the ATR," PG-T-92-114, EG\&G Idaho, Inc., July 1992.

14. 10 CFR 100, Appendix A, "Seismic and Geologic Siting Criteria for Nuclear Power Plants," Code of Federal Regulations, Office of Federal Register, January 10, 1977.

15. Nuclear Regulatory Guide 1.70, "Standard Format and Content of Safety Analysis Reports for Nuclear Power Plants," Rev. 3, U.S. Nuclear Regulatory Commission, Washington, D.C., November 1978. 
16. Nuclear Regulatory Guide 1.29, "Seismic Design Classification," U.S. Nuclear Regulatory Commission, Washington, D.C., September 1978.

17. DOE-STD-1020-2002, "Natural Phenomena Hazards Design and Evaluation Criteria for Department of Energy Facilities,” U.S. Department of Energy, April 2002.

18. ANSI/ANS 2.26-2004, "Categorization of Nuclear Facility Structures, Systems and Components for Seismic Design,” December 2004.

19. DOE-STD-1021-93, Change 1, "Natural Phenomena Hazards Performance Categorization Criteria for Structures, Systems, and Components," U.S. Department of Energy, April 2002.

20. DOE Order 420.1B, "Facility Safety,” U.S. Department of Energy, December 2005.

21. NS-18101, "INL Safety Analysis Process,” Rev. 3, May 2008.

22. DOE-STD-3009, Change Notice 3, "Preparation Guide for U. S. Department of Energy Nonreactor Nuclear Facility Documented Safety Analyses,” U.S. Department of Energy, March 2006. 